\title{
st \\ A teoria da prova em Leibniz
}

${ }^{\dagger}$ Mark Julian CAss

\begin{abstract}
$\stackrel{\sim}{\dddot{2}}$
RESUMO
\end{abstract}

Leibniz propôs que demonstrações fossem reformuladas como deduções a partir de identidades, e que proposições do tipo $A=A$ fossem a fonte única de verdade. Neste artigo, procuro explicar essa teoria da prova (e do conhecimento), assim como seus conceitos elementares, ou seja, os conceitos de identidade, verdade (ou possibilidade) e proposição (inclusive a teoria leibniziana da redutibilidade a proposições sujeito-predicado).

Palavras-Ghave • Prova. Identidade. Reductio ad absurdum. Verdade. Possibilidade. Leibniz.

\begin{abstract}
Admitir-se-á, então, que todos os enunciados de todos esses teoremas, que enchem tantos volumes, são, simplesmente, maneiras indiretas de $\operatorname{dizer} A$ é $A$ ?

Henri Poincaré (1984, p. 21).
\end{abstract}

\section{INTRODUÇÃO}

Este ensaio tem por propósito explicar a teoria da prova de Leibniz, assim como seus conceitos básicos, ou seja, os conceitos de identidade, de verdade e de proposição. Sua teoria difere, ao menos superficialmente, daquelas sugeridas pela silogística de Aristóteles e pela geometria euclidiana. Leibniz propôs que as ciências demonstrativas (a matemática e a geometria) fossem reelaboradas a partir de somente três ingredientes: definições (ou identidades supostas), identidades explícitas (proposições de forma $A=A$ ), e uma regra de inferência (a permissão de substituir quaisquer símbolos de um lado de uma identidade pelos símbolos do outro lado).

A inspiração e modelo desse modo de estruturar as ciências demonstrativas foi, sem dúvida, a aritmética. Não irei avaliar a possibilidade de realizar o projeto leibniziano, pois, com respeito à geometria, não há registro de um empenho por parte de Leibniz em realizá-lo. A possibilidade de uma geometria de feição leibniziana, com toda a riqueza da versão euclidiana, tem sido questionada (cf. Poincaré, 1984, cap. 1). 
Todavia, veremos que sua apreciação do alcance ou importância das ciências demonstrativas (especialmente da geometria) difere marcadamente da apreciação de seus contemporâneos e antecessores. Pelo menos com respeito a isso, sua teoria da prova merece atenção.

\section{O AXIOMA DE IDENTIDADE}

Em Primeiras verdades (Primae veritates) e Novos ensaios sobre o entendimento humano, Leibniz propôs como a fonte última da verdade dos teoremas das ciências demonstrativas o "axioma de identidade". Leibniz formula esse princípio de várias maneiras, por exemplo, " $A$ é idêntico a $A$ ", " $A$ é o mesmo que $A$ ", " $A$ não é não $A$ ", "cada coisa é o que é" e "cada coisa é igual a si mesma". Entretanto, a versão predominante do axioma em alguns escritos que registram seus esforços em lógica simbólica é a fórmula " $A=A$ " ou seja, " $A$ é igual (ou idêntico) a $A$ ". De acordo com o axioma de identidade, todas as sentenças desse tipo são verdadeiras.

Ao chamar " $A=A$ " de "axioma", Leibniz talvez quisesse evocar a teoria da ciência de Aristóteles. Nos Segundos analíticos (Livro I, cap. 2), Aristóteles (1994) reserva o termo "axioma" para qualquer sentença ou regra suposta por todas as ciências. Por outro lado, ele chama de "teses" as suposições - definições ou hipóteses - específicas de cada ciência. Dentre os exemplos de axioma oferecidos por Aristóteles, encontramos os chamados princípios do terceiro excluído e de contradição. Tais princípios são duas suposições determinantes do silogismo, a forma básica de inferência científica, segundo sua teoria da ciência. De maneira análoga, os conceitos leibnizianos de demonstração e de ciência demonstrativa são moldados por seu axioma de identidade. Leibniz argumenta que qualquer ciência demonstrativa pode ser transformada em um sistema, também de caráter dedutivo, cuja base consiste inteiramente de identidades, tanto de identidades explícitas (do tipo $A=A$ ), como de definições (identidades supostas ou "implícitas"). ${ }^{\mathbf{S}}$ Segundo seu conceito de demonstração, a verdade de uma tese será estabelecida se for mostrado que ela segue dedutivamente de um conjunto de definições e de pelo menos uma identidade do tipo $A=A$. Definições são simbolizadas pela equação " $A=B C$ ", na qual $A$ é o definiendum e a conjunção de $B$ e $C$, o definiens, e têm por função facultar a substituição de um definiendum por seu definiens, e vice versa. ${ }^{2}$

1 “(...) as significações dos termos, isto é, as definições, junto aos axiomas idênticos exprimem os princípios de todas as demonstrações (...)” (Leibniz, 1999, p. 431).

2 Uma questão sem uma resposta definitiva dada por Leibniz diz respeito à classificação de definições como proposições ou apenas permissões de substituição. Em Primeiras verdades, Leibniz sustenta que definições são identidades "implícitas", e, por isso, verdades (Leibniz, 1995 [1686], p. 87-8). No entanto, ele escreve em Novos ensaios "que 
Por sua vez, as identidades explícitas são caracterizadas por Leibniz como verdades autoevidentes, e, segundo alguns de seus escritos, todos os teoremas de uma ciência demonstrativa ou são identidades explícitas ou devem a sua verdade a tais identidades. ${ }^{3}$ Ou seja, a fórmula $A=A$ seria uma espécie de premissa universal das ciências demonstrativas de feição leibniziana.

\section{Provas POR REDUÇÃo A UMA IDENTIDADE}

Chamaremos o tipo de prova delineada por Leibniz em Primeiras verdades e Novos ensaios de "redução a uma identidade" (RAI), devido a sua relação estreita com as provas por "redução ao absurdo" (RAA). Leibniz sugere dois métodos de prova por RAI: pelo método canônico (ou "sintético"), a proposição a ser provada é deduzida de identidades, enquanto pelo método analítico, uma identidade é derivada da proposição a ser provada. No entanto, devemos salientar que ele somente apresenta resumos e modelos de argumento na forma canônica, e que, quando fala de "redução a identidades", talvez tenha apenas tais argumentos em mente.

Em Primeiras verdades, Leibniz nos oferece uma prova por RAI da proposição segundo a qual "uma parte [própria] do todo é menor do que o todo" ou, em outras palavras, para facilitar a compreensão da prova, "dado qualquer agregado $B$, uma parte de $B$ é menor que $B$ ". Seguem os passos de sua prova de tal "lei" pelo método canônico:

(1) Uma definição de "menor" é proposta: " $X$ é menor do que $Y$ " $\equiv$ " $X$ é igual a uma parte de $Y^{\prime \prime}$.

(2) Uma identidade explícita é afirmada: "uma parte de B é igual a uma parte de B".

um mais um é igual a dois, não é propriamente uma verdade, mas a definição de dois” (Leibniz, 1999, p. 4,08). Isto sugere que Leibniz considera o definiendum de uma definição como uma maneira contingente ou apenas convencionada de designar um conceito (ou um gênero, ou um existente possível), e que o princípio do terceiro excluído não se aplica a convenções propostas. Mesmo assim, dada uma definição expressa como uma identidade, a afirmação da identidade dos designados pelo definiendum e definiens deve ser verdadeira (ou seja, definições qua proposições são identidades do tipo $A=A$ camufladas). Consideremos o exemplo de sempre: a sentença "solteiros são homens não casados" não é uma sentença declarativa (ou um portador de valor de verdade) se entendida como uma proposta - a saber, a de usar a palavra "solteiro" no sentido indicado. No entanto, uma vez aceita a proposta, a mesma sentença pode ser lida como uma afirmação verdadeira, visto que os designados pelos termos "solteiro" e "homens não casados" devem ser exatamente os mesmos.

3 Em Primeiras verdades, ele escreve que "todas as outras verdades são reduzidas às primeiras verdades [ou seja, a identidades explícitas] por meio de definições - quer dizer, pela análise de conceitos; e isto constitui uma prova a priori, independente da experiência" (Leibniz, 1995 [1686], p. 87). 
(3) Se substituirmos o definiens de (1) pela identidade (2), obteremos, no definiendum de (1), "uma parte de $B$ é menor do que $B$ ", que é a proposição a ser provada.

Algumas provas aritméticas podem ser facilmente expressas como provas por RAI. Consideremos a igualdade $5=3+2$. Os números 2, 3 e 5 podem ser definidos como somas de uns $(2=1+1$ etc. $)$. A partir das definições e da identidade $1+1+1+1+1=1+1+$ $1+1+1$, a igualdade original pode ser derivada.

Em Primeiras verdades, Leibniz também sugere que as conclusões dos argumentos acima poderiam ser provadas pela "análise de conceitos" (Leibniz, 1995 [1686], p. 87), mais precisamente, pela análise dos termos das conclusões baseada em definições. Por esse método, a verdade de uma tese será estabelecida se uma identidade explícita for descoberta a partir da substituição dos termos da tese em pauta por suas definições. Por exemplo, a partir da igualdade $5=3+2$ e das definições de seus números, alcançamos a identidade $1+1+1+1+1=1+1+1+1+1$. As partes desta prova por RAI (analítica) são indicadas a seguir:

$$
\begin{aligned}
\text { Analisandum: } & =3+2 \\
\text { Definições: } & 5=1+1+1+1+1 \\
3 & =1+1+1 \\
2 & =1+1
\end{aligned}
$$

As duas inferências são propriamente descritas como provas ou demonstrações, porque, no primeiro caso, a proposição a ser provada é deduzida de uma verdade (a identidade explícita) e de permissões de substituição (definições) e, no segundo, descobre-se, a partir de permissões de substituição, que a proposição a ser provada pode ser expressa como uma identidade explícita (e, por isso, ela deve ser verdadeira).

Tendo em vista que as definições em ambas as estruturas são permissões de substituição de mão dupla, se uma prova (canônica ou analítica) for possível, a outra também deve sê-lo.

Provas por RAI e por RAA também podem ser transformadas umas nas outras. Provas por RAI exemplificam a seguinte regra:

(1) Se (T, $D) \Rightarrow P$, então a proposição $P$ é verdadeira.

Neste condicional, $P$ é uma proposição, T uma identidade explícita e $D$ uma definição ou um conjunto de identidades supostas. A regra (1) afirma que, se $P$ é uma 
consequência dedutiva de T e $D$ ( $\Rightarrow$ simboliza consequência dedutiva), então a proposição $P$ é verdadeira. A seguinte regra RAA é um corolário da regra (1):

(2) Se (não-P,D) $\Rightarrow \perp$, então a proposição $P$ é verdadeira. ${ }^{4}$

Em outras palavras, se, dadas as definições, a negação de $P$ tiver uma contradição $(\perp)$ como consequência dedutiva, então $P$ é verdadeira. A regra (2), por sua vez, é um corolário da regra (1). À primeira vista, provas por RAI e por RAA são apenas superficialmente distintas, apenas duas faces da mesma moeda.

Essa relação entre provas por RAI e por RAA incita a seguinte pergunta: por que Leibniz às vezes elabora sua teoria da demonstração sobre o excêntrico axioma de identidade em vez de sobre o ortodoxo princípio de contradição ${ }^{5}$ Além do modelo aritmético, sugiro as seguintes respostas. A proposição " $A$ é $A$ " é mais simples que " $A$ não é $A$ " e, por isso, a verdade daquela seria mais evidente que a falsidade desta. Em segundo lugar, Leibniz propõe como único critério de verdade - não só na lógica e na matemática, mas na metafísica - a identidade de termos. Em terceiro, a substituição de idênticos é a única regra de inferência suposta por Leibniz em seus cálculos lógicos. Por fim, é por meio do seu axioma de identidade que Leibniz demarca sua concepção de demonstração da teoria tradicional. De acordo com esta última, a verdade dos postulados de uma ciência seria de alguma maneira garantida pela experiência, ou seja, pela experiência sensorial ou introspectiva. Mas Leibniz considera tais razões inadequadas ou impróprias para uma ciência. Sobre a evidência fornecida pelos sentidos "externos" ele escreve:

\begin{abstract}
(...) todos os exemplos que confirmam uma verdade de ordem geral, qualquer que seja o seu número, não são suficientes para estabelecer a necessidade universal desta mesma verdade, pois não segue que aquilo que aconteceu uma vez tornará a acontecer da mesma forma (Leibniz, 1999, p. 23). ${ }^{6}$
\end{abstract}

\footnotetext{
4 Neste condicional, o símbolo $\perp$ representa a negação de uma identidade explícita. Em Leibniz, contradições ou são negações de identidades explícitas ou podem ser reduzidas a proposições deste tipo.

5 Segundo este princípio, qualquer contradição (ou proposição que implica uma contradição) é falsa. Em alguns escritos, Leibniz elege o princípio de contradição como fundamental (por exemplo, na Monadologia, §31, Leibniz, 1974 [1714], p. 66). Em outros ele menciona ambos: "O grande fundamento dos matemáticos é o princípio da contradição ou da identidade, isto é, que um enunciado não poderia ser verdadeiro e falso ao mesmo tempo, e que assim $A$ é $A$, e não poderia ser não- $A$ " (Leibniz, 1974 [1715-16], p. 407). Isto sugere que, pelo menos de um ponto de vista lógico, Leibniz considerava provas por RAI e por RAA intercambiáveis. Todavia, de um ponto de vista lógico, pode haver uma razão para preferir provas por RAI a provas por RAA, se o princípio do terceiro excluído ou o de contradição for recusado. Mas Leibniz não questiona esses princípios.

6 A aporia aqui explicada é mais conhecida como "o problema de Hume".
} 
E sobre a evidência introspectiva:

Euclides, por exemplo, colocou entre os axiomas o que equivale a dizer que duas linhas retas só podem encontrar-se uma vez. A imaginação, tomada da experiência dos sentidos, não nos permite imaginar mais de um encontro entre duas retas, porém a ciência não pode fundar-se sobre tal afirmação (Leibniz, 1999, p. 454).

Para Leibniz, as generalizações derivadas da experiência sensorial e da introspecção são precárias pela mesma razão. Ele não questiona o quinto postulado, mas, sobre tais verdades, argumenta que

(...) não as encontramos pela indução dos exemplos. Aquele que conhece que dez são mais do que nove, que o corpo é maior do que o dedo, e que a casa é grande demais para poder sair pela porta, conhece cada uma dessas proposições particulares por uma mesma razão geral que está como que incorporada e iluminada (...). Ora, esta razão comum é o próprio axioma que é conhecido, por assim dizer, implicitamente, embora não o seja imediatamente de uma forma abstrata e separada. Os exemplos tiram a sua verdade do axioma incorporado e o axioma não tem o seu fundamento nos exemplos (Leibniz, 1999, p. 451-2).

O axioma mencionado nestas sentenças é que "o todo é maior que a sua parte". Como vimos no primeiro argumento examinado nesta seção, o axioma "incorpora" uma identidade explícita.

\section{IDENTIDADE E VERDADE DEFINIDAS}

Em várias ocasiões, Leibniz afirma que nossa certeza sobre a verdade de identidades explícitas é inabalável, que elas não podem ser demonstradas por proposições mais evidentes, e que são imediatamente percebidas como verdadeiras (Leibniz, 1999, p. 364). No entanto, para esclarecer por que elas são destacadas de proposições consideradas autoevidentes por outros filósofos ou matemáticos (como foram alguns postulados de Euclides), torna-se necessário examinar seus conceitos de "verdade" e "identidade". ? Por outro lado, uma decisão ponderada sobre a verdade de $A=A$ depende do sentido atribuído a "=" e à palavra "verdade". Começaremos pela ideia de identidade.

${ }_{7} \mathrm{O}$ axioma de identidade não é uma definição de identidade; ele se limita à afirmação de que identidades explícitas são verdadeiras. Veremos que, se a definição de identidade proposta por Leibniz for aceita, a verdade do axioma é pacífica. 
Em seus escritos lógicos, uma definição salva veritate de identidade é geralmente recitada. Assim, no manuscrito Um estudo no cálculo de adição real, por exemplo, ele escreve:

Termos são "iguais" ou "coincidentes" se um pode ser substituído pelo outro, onde quer que se queira, sem perda de verdade - por exemplo, "triângulo" e "trilateral". Pois, em todas as proposições sobre o "triângulo" provadas por Euclides, "trilateral" pode ser substituído sem perda de verdade, e vice versa. (Leibniz, 1966 [1690], p. 131).

No entanto, por não termos ainda definido "verdade", tomaremos como referência uma definição de identidade das Investigações gerais (Generales inquisitiones):

[Dizemos que] " $A$ e $B$ coincidem" (...) se, ao analisarmos cada um dos dois [ter$\operatorname{mos} A$ e $B$ ] pela substituição dos seus valores (ou seja, pelas suas definições) nos lugares dos seus termos, os mesmos termos [nos definientia] aparecem em ambos os lados (...) (Leibniz, 1966 [1686], p. $\left.5^{3}\right)$.

Essa definição - conhecida como a "lei de Leibniz" e pressuposta pelo princípio metafísico de identidade de indiscerníveis - ${ }^{\mathbf{8}}$ pode ser colocada de maneira mais precisa dizendo que os termos $A$ e $B$ são idênticos, se (mas somente "se") não há nenhuma propriedade ou parte de $A$ que não seja também uma propriedade ou parte de $B$, e vice versa (cf. Tarski, 1941, p. 51).

Se for admitida essa definição de identidade, seria contraditório afirmar que $A$ e $B$ têm as mesmas propriedades e negar que são idênticos, ${ }^{9}$ ou, portanto, que as pro-

8 "É mesmo preciso todas as mônadas diferirem entre si, porque na natureza nunca há dois seres perfeitamente idênticos, onde não seja possível encontrar uma diferença interna, ou fundada em uma determinação intrínseca" (Monadologia, §9, Leibniz, 1974 [1714], p. 63). O conceito de identidade sugerido por essa hipótese é que os seres são idênticos se não diferirem em pelo uma de suas propriedades (ou "determinações intrínsecas").

9 Com respeito à noção leibniziana de termo, não há em seus escritos lógicos uma clara restrição àquilo que um termo pode designar ou representar - um termo pode ser o sujeito ou predicado de uma proposição categórica, um nome próprio, uma descrição ou um conceito, uma coisa, um agregado, um "possível”, ou uma proposição (cf., por exemplo, Leibniz, 1966, p. 17, 39, 51, 71). Ambas as definições leibnizianas de identidade (a definição salva veritate e a lei de Leibniz) são insuficientes, pelo menos por não estipularem nenhuma restrição a termos "reflexivos" nos seus definienda: segundo Leibniz, a definição salva veritate de identidade (e o mesmo vale para a lei de Leibniz) pode falhar se um termo representa um objeto enquanto relacionado a outro: por exemplo, mesmo que uma única pessoa é designada por "o primeiro papa da Igreja católica" e por “o apóstolo que negou a Cristo", essas descrições não são idênticas. Proposições reflexivas, Leibniz escreve, "antes de afirmarem algo sobre uma coisa, versam sobre nossa maneira de concebê-la (...)" (Leibniz apud Mates, 1989, p. 131). No que segue, faremos vista grossa a esse tipo de problema. 
priedades de $A$ e $A$ coincidem, e negar que $A$ é igual a si mesmo. Como não há propriedade de $A$ que não seja própria de $A$, a afirmação de que $A$ é idêntico a $A$ é concordante ou condizente com a definição, e a sua negação a contradiz.

E isso sugere - tendo em vista que ele descreve como verdadeira a proposição $A=A$ e como falsa a sua negação - que Leibniz definiria "verdadeiro" como "concorda com as definições supostas", e "falso" como "contradiz as definições supostas". Tal definição de falsidade pode ser formulada da seguinte maneira:

(3) A sentença $P$ é falsa, se, e somente se, dadas as definições $(D)$ dos termos em $P, P$ implica uma contradição.

A seguinte definição de verdade segue de (3):

(4) A sentença $P$ é verdadeira, se e somente se, dadas as definições dos termos em $P$, não- $P$ implica uma contradição.

Usando alguns símbolos já explicados, (4) pode ser reescrita da seguinte maneira:

$\left(4^{*}\right)$ A sentença $P$ é verdadeira, se, e somente se, (não- $\left.P, D\right) \Rightarrow \perp$.

Ou como:

$\left(4^{* *}\right)$ A sentença $P$ é verdadeira, se, e somente se, $(\mathrm{T}, D) \Rightarrow P$.

Uma metade desse bicondicional reclama atenção (a outra já foi explicada). De acordo com essa definição, se uma proposição é verdadeira, existe uma prova da proposição (mais precisamente, uma prova por substituição a partir de identidades explícitas ou assumidas). A tese de que existe uma prova de qualquer verdade equivale a algumas formulações leibnizianas do princípio de razão suficiente. Portanto, sugerimos que esse princípio é fornecido pela própria ideia leibniziana de verdade, e que essa ideia pode ser colhida de proposições do tipo "uma coisa é idêntica a si mesma", da afirmação de que essas são verdadeiras e da lei de Leibniz.

\section{A teoria leibNiziana da PRoposição}

Atribuímos a Leibniz a tese de que toda proposição verdadeira ou é uma identidade do tipo $A=A$, ou pode ser reduzida a uma identidade explícita. Por sua vez, proposições falsas ou são contradições ou implicam contradições, e podem ser reduzidas a negações de identidades explícitas. No entanto, as sentenças declarativas de linguagens 
naturais, inclusive a linguagem da ciência, não são afirmadas nem negadas na forma de identidades. A forma básica de proposições expressas em linguagens naturais é, segundo Leibniz, “ $A$ (não) é $B$ ”. Portanto, ele sustenta que (1) proposições do tipo “ $A$ é $B$ ” são identidades ou contradições camufladas e (2) que outras proposições podem ser adequadamente expressas em termos de proposições do tipo “ $A$ é $B$ ”.

Leibniz entende que uma proposição do tipo “ $A$ é $B$ ” afirma que o termo predicado, $B$, é uma parte ou está contido no termo sujeito, $A$, e que isso equivale a dizer que $B$ é igual a uma parte do analisans de $A$, a saber, igual à parte $B \operatorname{de} A$. Para Leibniz, qualquer proposição verdadeira (seja ela sobre triângulos retos ou sobre uma vitória de Alexandre, o Grande) encerra uma identidade. Com respeito às ciências demonstrativas de feição leibniziana, indicamos que seus teoremas podem ser provados pela análise de conceitos. Proposições verdadeiras sobre o mundo, como, por exemplo, "Alexandre derrotou Dario", não diferem de teoremas matemáticos com respeito à existência de provas, pois se a sentença "Alexandre derrotou Dario" é verdadeira, deve existir uma prova de sua verdade (cf. $\left(4^{* *}\right)$ acima), mas com respeito à possibilidade de elaborarmos uma prova. Segundo Leibniz, não somos capazes de provar proposições verdadeiras sobre existentes, e ele oferece duas razões para tal limitação. Em primeiro lugar, coisas mundanas seriam "agregados" ou sistemas infinitamente complexos de propriedades (ou de partes), e isso seria, sem dúvida, uma barreira para a análise de conceitos por inteligências finitas. Em segundo lugar, ainda que fosse possível a análise dos "conceitos" de existentes, Leibniz argumenta que a existência não é uma propriedade essencial de coisas existentes, mas um atributo contingente do universo que elas habitam. ${ }^{10}$ Como a existência de existentes não pode ser descoberta pela análise de seus conceitos, a verdade por correspondência de enunciados sobre o mundo não pode ser demonstrada. Por tais razões, Leibniz sustenta que “(...) a física inteira jamais será uma ciência perfeita entre nós" (Leibniz, 1999, p. 456).

A tese (2) tem sido largamente comentada e criticada, especialmente seu corolário de que enunciados sobre relações são redutíveis a proposições do tipo " $A$ é $B$ ". " Aqui, procurarei determinar o que ele poderia ter sustentado a respeito de enunciados relacionais, tendo como premissa seu axioma de identidade. Antes de prosseguirmos, devemos salientar que proposições do tipo " $A$ é $B$ " - que pode ser lida como " $B$ é uma parte de $A "$ - são relacionais e, por isso, o problema a ser enfrentado por Leibniz não é o de reduzir enunciados do tipo Rab a complexos contendo Pi a e Pjb, mas o problema

10 Por ser um atributo contingente deste universo, a sua existência também não poderia ser revelada por análise. 11 Segundo Russell (1971, p. 12), "os exemplos mais claros de proposições que não são assim redutíveis são proposições que empregam ideias matemáticas”. No capítulo sobre Leibniz do História da filosofia ocidental, Russell afirama que "a lógica sujeito-predicado, que todos os filósofos desse tipo no passado assumiram, ou ignora por completo as relações, ou produz argumentos falaciosos para provar que as relações são irreais” (Russell, 1976, p. 575). 
não menos obstinado de reduzir diversos enunciados relacionais a sentenças sobre um único tipo de relação. ${ }^{\mathbf{1 2}}$

Uma característica distintiva de relações, reiterada por Leibniz, seria a de que a sua realidade é apenas ideal:

(...) [as] relações, que ligam duas mônadas, não se encontram nem em uma nem na outra, mas igualmente em ambas ao mesmo tempo, isto é, na verdade, em nenhuma das duas, mas apenas na mente (Leibniz, 1879 [1716], p. 517).

Para explicar a afirmação da idealidade de relações, é preciso voltar à metafísica leibniziana. Segundo Leibniz, o universo consiste apenas de mônadas, e estas consistem apenas de percepções. Dentre os tipos distintos de mônada, um ele chama de "alma racional" (Leibniz, 1974 [1714], p. 66), de modo que é de supor-se que percepções ou ideias de relações pertençam somente a tais mônadas. Algumas ideias de almas racionais não são apenas ideais. Por exemplo, a afirmação de Heródoto de que Candaules foi rei da Lídia é verdadeira, se, dentre as propriedades de Candaules, há a de ser rei da Lídia. Agora, dizer que enunciados sobre relações são apenas ideais implica que tais enunciados não são verdadeiros pela mesma razão, ou no mesmo sentido, que aquele sobre Candaules. À primeira vista, enunciados sobre relações não podem ser verdadeiros se a verdade é definida em termos de inclusão ou identidade. A verdade da afirmação de Heródoto de que Giges assassinou Candaules não pode ser caracterizada em termos de inclusão, pois, embora "Giges" e "Candaules" designem agregados monádicos, o termo que os liga não destaca um terceiro agregado, nem um agregado que eles possuam em comum (veja-se a citação acima). Enunciados do tipo " $A$ é $B$ " nos quais $B$ designa um predicado relacional são postulados por Leibniz como correspondentes monádicos, no plenum de enunciados relacionais: os correspondentes no plenum da ideia de que Giges assassinou Candaules é a propriedade de o primeiro ser o assassino de Candaules, e a deste de ser assassinado por Giges.

A redução proposta por Leibniz de enunciados relacionais a enunciados sobre propriedades relacionais pode ser resumida da seguinte maneira. Uma proposição relacional, $R$, é verdadeira, se há um conjunto de enunciados verdadeiros sobre agregados e suas partes $-P_{1}, \ldots, P_{n}$ - tal que não é possível que $P_{1}, \ldots, P_{n}$ sejam todos verdadeiros e $R$ falsa. A estrutura de uma redução ou dedução é a seguinte:

12 Leibniz reconhece que afirmações de inclusão são sobre relações: "Il vaut donc mieux placer les vérités dans le rapport entre les objets des idées, qui fait que l'une est comprise ou non comprise dans l'autre. ["É melhor, portanto, colocar as verdades na relação entre os objetos das ideias, o que significa que uma está incluída ou não está incluída na outra"] (Leibniz, 1921, p. 344-5). A tradução brasileira (em Os Pensadores) desta sentença é opaca. 
$P_{1}, \ldots, P_{n}$

Se $P_{1}, \ldots, P_{n}$, então $R$;

Portanto, $R$.

De acordo com vários filósofos, a posição defendida por Leibniz é a da equivalência de enunciados relacionais a conjuntos de enunciados do tipo " $A$ é $B$ ", nos quais $B$ representa uma propriedade (ou um predicado relacional) de $A$ (cf. Wong, 1980). Todavia, com respeito a várias relações, mesmo que a conjunção de " $P_{1}, \ldots, P_{n}$ " e "se $P_{1}$, $\ldots, P_{n}$, então $R$ " fosse verdadeira, "se $R$, então $P_{1}, \ldots, P_{n}$ " poderia ser falsa. Por exemplo, ainda que Platão tinha que ser mais alvo do que Sócrates por causa das respectivas propriedades intrínsecas de cada um, é possível que Platão fosse mais alvo do que Sócrates, mas que eles não tivessem as propriedades que tiveram. Além do mais, não há função a ser realizada pelo condicional "se $R$, então $P_{1}, \ldots, P_{n}$ " na epistemologia e na lógica leibnizianas. Leibniz sustenta que os enunciados relacionais podem ser ignorados porque são implicados por proposições do tipo “ $A$ é $B$ ”, porque qualquer conse-

quência, $S$, do enunciado relacional, $R$, também será uma consequência daqueles enunciados sobre as propriedades relacionais que implicam $R$ : se $R \Rightarrow S$, e $\left(P_{1}, \ldots, P_{n}\right) \Rightarrow R$, então $\left(P_{1}, \ldots, P_{n}\right) \Rightarrow S$.

\section{Considerações Finais}

Provas são convencionalmente definidas em termos de verdade e a verdade é convencionalmente definida em termos de correspondência com a realidade. Leibniz argumenta pela moderação das nossas expectativas sobre o alcance ou importância das provas, fornecendo uma ideia clara e adequada (e cética) do que é uma prova. Através de uma prova por RAA, a falsidade, ou melhor, a inconsistência ou impossibilidade de uma tese é estabelecida; uma prova por RAI, sendo apenas uma reformulação intercambiável de uma prova por RAA, não estabelece a verdade por correspondência de uma tese derivada, mas apenas a consistência ou a possibilidade desta. Leibniz propõe tais redefinições de verdade e falsidade nos Novos ensaios:

(...) prefiro denominar as ideias verdadeiras ou falsas, tomando como ponto de referência outra afirmação tácita, que todas elas encerram: a da possibilidade. Assim sendo, as ideias possíveis são verdadeiras, as impossíveis sãofalsas (Leibniz, 1999, p. 251). 
Embora Leibniz não expresse dúvida alguma sobre a aplicabilidade da geometria euclidiana ao universo físico, sua teoria da prova encoraja a expectativa, confirmada na primeira metade do século xix, de que diversas geometrias possíveis fossem desenvolvidas.

Elogio. Este artigo publicado pela Scientiae Studia foi submetido pelo autor, Mark Julian Cass (1957-2013), poucos meses antes de seu súbito falecimento. Coube a mim, aluno que fui do Inglês - tal como fora apelidado pelo professor Bento Prado Jr. -, escrever esta brevíssima nota. Das diversas qualidades do Julian, as que mais se faziam notar eram a sua imensa modéstia intelectual, a sua incansável dedicação aos alunos e a sua disposição em fazer variadas e duradouras amizades. Em que pese a ausência do pensador, do lógico rigoroso e do professor paciente, o que mais consternou a todos os que o conheceram foi, sem sombra de dúvida, a perda do amigo. Ocorre que por detrás da aparência, quiçá ligeiramente intimidante a primeira vista, havia um coração de ouro. E isso se refletia plenamente no exame que fazia das ideias de quem quer que fosse: Julian era simplesmente incapaz de lançar críticas sem antes ressaltar o que porventura houvesse de proveitoso no pensamento dos interlocutores. Em virtude disso, era daqueles professores que despertava no alunado o indelével sentimento de philia. Sua morte prematura deixou um enorme vazio que, de alguma forma, atenua-se, de maneira muito ligeira, conquanto significativa, com a publicação deste seu último trabalho (Renato Kinouchi).

${ }^{\dagger}$ Mark Julian CAss Departamento de Filosofia e Metodologia das Ciências, Universidade Federal de São Carlos, Brasil.

\title{
Leibniz's theory of proof
}

\begin{abstract}
Leibniz proposed that demonstrations be reformulated as deductions from identities, and that propositions of the type $A=A$ be the only source of truth. In this article, I aim to explain this theory of proof (and knowledge), as well as its elementary concepts, such as identity, truth (or possibility) and proposition (including Leibniz's theory of reducibility of propositions to subject-predicate form).
\end{abstract}

KEYwords • Proof. Identity. Reductio ad absurdum. Truth. Possibility. Leibniz.

\section{REFERÊNGIAS BIBLIOGRÁFIGAS}

Aristóteles. Posterior analytics. Tradução J. Barnes. 2 ed. Oxford: Clarendon Press, 1994.

Broad, C. D. Leibniz, an introduction. London: Cambridge University Press, 1975.

Gerhardt, C. F. (Org.). Die philosophischen Schriften von Gottfried Wilhelm Leibniz. Berlin: Weidmannsche Buchhandlung, 1879 .

Leibniz, G. W. Briefwechsel zwischen Leibniz und des Bosses (1706-1716). In: Gerhardt, G. F. (Org.). Die philosophischen Schriften von Gottfried Wilhelm Leibniz. Berlim: Weidmannsche Buchhandlung, ${ }_{1879 .}$ v. 2, p. $284,-521$. 
Nouveaux essais surl'entendement humain. Paris: Flammarion, 1921.

. Logical papers. Tradução G. H. R. Parkinson . Oxford: Clarendon Press, 1966.

. Correspondência com Clarke. Tradução C. L. de Mattos. São Paulo: Abril Cultural, 1974 [1715-16].

p. 4,01-68. (Os Pensadores, v. 19).

. Monadologia. Tradução M. S. Chauí Berlinck. São Paulo: Abril Cultural, 1974 [1714]. p. 61-73. (Os

Pensadores, v. 19).

Primary truths. In: Morris, M. \& Parkinson, G. H. R. (Ed.). Philosophical writings of G. W. Leibniz.

London: Dent, 1995 [1686]. p. 87-92.

Novos ensaios sobre o entendimento humano. Tradução L. J. Baraúna. São Paulo: Nova Cultural, 1999. (Os Pensadores).

Mates, B. The philosophy of Leibniz. New York: Oxford University Press, 1989.

Morris, M. \& Parkinson, G. H. R. (Ed.). Philosophical writings of G. W. Leibniz. London: Dent, 1995 [1686].

MugnaI, M. Leibniz' theory of relations. Stuttgart: Franz Steiner, 1992.

Poincaré, H. A ciência e a hipótese. Brasília: Editora Universidade de Brasília, 1984.

Rescher, N. G. W. Leibniz's Monadology. London: Routledge, 1991.

Russeld, B. A critical exposition of the philosophy of Leibniz. London: George Allen \& Unwin, 1971. History of western philosophy. London: George Allen \& Unwin, 1976.

TARSKI, A. Introduction to logic. New York: Oxford University Press, 1941.

Wong, D. Leibniz's theory of relations. Philosophical Review, 89, 2, p. 2411-56, 1980. 